\title{
Can Oxidative Stress Induced by Obstructive Jaundice be Improved by Iloprost? An Experimental Study in Rats
}

\author{
Onur Bayraktar ${ }^{1}$, Barış Bayraktar ${ }^{2}$, Ilknur Erenler ${ }^{1}$ \\ ${ }^{1}$ T.C. Istanbul Bilim University, School of Medicine Department of General Surgery, Istanbul-Turkey \\ ${ }^{2}$ Konak Hospital, Department of General Surgery, Gebze, Kocaeli
}

\begin{abstract}
Background/Aims: Iloprost is a synthetic analogue of epoprostenol which is synthesized by endotelial cells from arachidonic acid. We aimed to evaluate presumed hepatoprotective and antioxidant effects of iloprost in experimentally created obstructive jaundice in rats.

Materials and Methods: Thirty-two adult male Wistar albino rats were randomly divided into four groups: sham group $(\mathrm{S})(\mathrm{n}=8)$; after sham operation, iloprost administered $(\mathrm{SI})$ group $(\mathrm{n}=8)$; obstructive jaundice $(\mathrm{OJ})$ group $(n=8)$; iloprost administered and obstructive jaundice group (OJI) $(n=8)$. The rats were sacrified ten days after the induction of obstructive jaundice. Blood levels of isoprostane, protein carbonyl, lipid hydroperoxide and 8-hydroxy-2-deoxyguanosine (8-OHdG) were measured.

Results: Levels of the oxidative stress products including protein carbonyl [mean, (40.46 versus 24.7 $\mathrm{nmol} / \mathrm{ml}, \mathrm{p}=0.005)]$, lipid hydroperoxide [mean, (5.11 versus $1.85 \mathrm{Mmol} / \mathrm{ml}, \mathrm{p}=0.001)$ ] and 8 OHdG[mean, $(1.53$ versus $1.13 \mathrm{ng} / \mathrm{ml}, \mathrm{p}=0.03)]$ in the OJI group were significantly lower than the OJ group.

Conclusion: Iloprost supports antioxidant activity in obstructive jaundice without causing further liver damage in rats.

Keywords: Antioxidants, bile duct ligation, experimental study, iloprost, obstructive jaundice, oxidative stress.
\end{abstract}

\section{Introduction}

Obstructive jaundice is a clinical entity occurring after blockage of bile flow from the liver to the small intestine. Direct hyperbilirubinemia developed after obstruction of bile flow causes several disruptions including immune suppression, liver toxicity, coagulation disorders, intestinal barrier damage, increased oxidative stress, bacteremia and endotoxemia (Guicciardi et al. 2013). Oxidative stress is an imbalance between the production and degradation of reactive oxygen species in vivo. It damages the hepatocytes and intestinal cells in obstructive jaundice (Liu et al. 2001, Assimakopoulos et al. 2004a, Vendemiale et al. 2002, Assimakopoulos et al. 2004b, Assimakopoulos et al. 2006). Patients with obstructive jaundice are prone to develop serious complications during treatment process such as sepsis, renal complications and even death (Pain et al. 1985). Oxidative stress has a major role in the pathogenesis of hepatic injury and sepsis (Vendemiale et al. 2002, Allemeh et al. 2012). New treatment alternatives reducing oxidative stress may be effective to prevent complications associated with obstructive jaundice.

Iloprost is a synthetic analogue of epoprostenol (prostoglandin $I_{2}$, prostacyclin) which is synthesized by endothelial cells from arachidonic acid. Beside the vasodilatory, antiplatelet and cytoprotective effects of the iloprost, it has fibrinolytic activity and it increases red cell elasticity, increases smooth muscle proliferation and supports microcirculation (Della Bella et al. 2001, Grant and Goa 1992). Considering its beneficial effects, iloprost seems as a good candidate to be evaluated experimentally against oxidative stress induced by obstructive jaundice. In this study, the effects of systematic application of iloprost on oxidative stress parameters and liver histopathology were assessed in rats with obstructive jaundice. This is the first study showing antioxidant effects of iloprost against oxidative stress induced by obstructive jaundice. 


\section{Materials and Methods}

The Ethics Committee of Experimental Animal Research of our university approved the study protocol. Thirty two Wistar-Albino male rats, weighing 250-300g, were used. The rats were housed four in per cage, under constant temperature $\left(20-22^{\circ} \mathrm{C}\right)$ and humidity $(50 \mathrm{~F})$ with an artificial 12 hour light-dark cycle and randomized into four groups. Obstructive jaundice was induced by ligation of the common bile duct. The rats were fed ad libitum with standardized industrial rat prey during the study period except 12 hours prior to operation. Twelve hours before the operation feeding was stopped. The rats were divided randomly into four equal weight-matched groups containing eight rats each. The study groups were sham (S) group; after sham operation, intraperitoneal iloprost applied (SI) group; obstructive jaundiced (OJ) group (the control group); after obstructive jaundice induction, intraperitoneal iloprost applied (OJI) group. A daily dose of $2 \mathrm{mcg} / \mathrm{kg}$ iloprost was given to the rats in the SI and OJI groups. Beneficial effects of the same dose iloprost in Wistar rats were shown previously (Vasiliadis et al. 2007). The S and OJ groups had been administered daily same volume $0.9 \% \mathrm{NaCl}$ solution intraperitoneally, while the others receiving iloprost injections. Ten days after the induction of obstructive jaundice, blood samples were taken with intra cardiac puncture under general anesthesia. A cervical dislocation was performed before liver tissue sampling.

\section{Bile duct ligation}

The rats were anesthetized by intraperitoneal administration of $100 \mathrm{mg} / \mathrm{kg}$ ketamine hydrochloride (Ketalar; Parke- Davis, Istanbul, Turkey) and $5 \mathrm{mg} / \mathrm{kg}$ xylasine (Rompun; Bayer, Istanbul, Turkey). A $2 \mathrm{~cm}$ midline incision was made. In the Sham groups, the gastroduodenal ligament was isolated and the common bile duct was mobilized without any ligation or division. In the obstructive jaundice groups, the common bile ducts were ligated from 2 different points in middle with 4/0 silk sutures after common bile duct mobilization and divided. The abdominal incisions were closed in two layers with continuous 4/0 polyglactin and 4/0 silk sutures respectively. After the procedure, the rats were put into the cages.

\subsection{Biochemical Analyses}

The blood samples were stored in silicone tubes. The blood samples were centrifuged for five minutes at $6500 \mathrm{rpm}$. The serums were then separated.

The analysis of plasma 8-hydroxy-2-deoxyguanosine (8-OHdG), an indicator of oxidative damage on DNA, was made with competitive ELISA method using ELISA kits (NWLSS ${ }^{\mathrm{TM}}$ 8-OHdG ELISA, Northwest Vancouver, Canada). The concentration of samples was calculated using the standard calibration curve. The standard concentration ranges were $0.125 \mathrm{ng} / \mathrm{ml}, 0.250 \mathrm{ng} / \mathrm{ml}, 0.5 \mathrm{ng} / \mathrm{ml}, 1 \mathrm{ng} / \mathrm{ml}, 4 \mathrm{ng} / \mathrm{ml}$ and $10 \mathrm{ng} / \mathrm{ml}$ respectively.

The plasma isoprostane possesses potent biological activity and are released from tissues in a number of disease states, such as during ischemic injury and neurodegenerative brain disease. The measurement of isoprostane is considered to be the «gold standard» to assess oxidative stress in various human diseases. The analysis of isoprostane was made with competitive ELISA method using ELISA kits (NWLSS ${ }^{\mathrm{TM}}$ 8-OHdG ELISA, Northwest, Vancouver, Canada). The concentration of samples was calculated using the standard calibration curve, and the concentration ranges were $0.005 \mathrm{ng} / \mathrm{ml}, 0.1 \mathrm{ng} / \mathrm{ml}, 1 \mathrm{ng} / \mathrm{ml}, 5 \mathrm{ng} / \mathrm{ml}, 10 \mathrm{ng} / \mathrm{ml}, 50$ $\mathrm{ng} / \mathrm{ml}, 100 \mathrm{ng} / \mathrm{ml}$ respectively.

The plasma protein carbonyl, which reveals after the oxidation of amino-acid chains,

analysis was made using a commercial kit (NWLSS ${ }^{\mathrm{TM}}$ Protein Carbonyl Assay, Northwest, Vancouver, Canada) based on spectrophotometric principles. Absorbance of the samples was measured at a wavelength of $320 \mathrm{~nm}$. Concentrations of the samples were measured by using molar absorptivity coefficient $\left(22.000 \mathrm{M}^{-}\right.$ ${ }^{1}, \mathrm{~cm}^{-1}$ ) of protein carbonyl.

The plasma lipid hydroperoxide (LOOH), an indicator of the peroxidation of lipids and damage of the cell membrane, analysis was made using a commercial kit $\left(\right.$ NWLSS $^{\mathrm{TM}}$ Protein Carbonyl Assay, Northwest, Vancouver Canada) based on spectrophotometric principles. Absorbance of the samples and calibrator was measured at a wavelength of $560 \mathrm{~nm}$. Concentrations of the samples were measured by using molar absorptivity coefficient $\left(33.700 \mathrm{M}^{-1}, \mathrm{~cm}^{-1}\right)$ of protein carbonyl. 


\subsection{Histopathologic Examination}

The liver samples were placed in $10 \%$ buffered formaline solution for 3 hours. After alcohol, acetone, xylene and paraffin procedures, the blocks were prepared. Then four microns cuts were obtained from the blocks and they were stained with hematoxylin and eosin (H\&E) stain. Knodell index was used for histologic grading and staging (Knodell et al. 1981). The prepared slides were evaluated under light microscope with magnification of 40x and 100x. Their photos were taken by the camera connected to the microscope. The slides were assessed between - (0) and +++ (3) according to adiposity, hydropic degeneration, Kupffer cell proliferation/ sinusoidal cell proliferation, bile stasis, inflammatory activity in portal space (mononuclear cell infiltration), bile stasis, cholangitis (neutrophil and mononuclear cell infiltration to bile ducts), micro abscess formation.

\subsection{Statistical Analysis}

The data were presented as mean \pm standard deviation. Differences among the groups were evaluated by Kruskal-Wallis test by using SPSS 12 (SPSS Inc. Chicago USA). P values less than 0.05 were considered significant. When statistically significant values were identified, Mann-Whitney U test was used for paired comparisons and Bonferroni correction was used to detect statistical significance. $\mathrm{P}$ values less than 0.0083 were considered significant.

\section{Results}

No rats died during study period.

Biochemical parameters

There was no statistically significant difference in biochemical parameters between $\mathrm{S}$ and SI groups (Table 1). 8-OHdG ( $\mathrm{p}=0.006)$, isoprostane $(\mathrm{p}=0.003)$, lipid hydroperoxide $(\mathrm{p}=0.001)$ parameters were found to be increased in OJ group compared to $\mathrm{S}$ group. Protein carbonyl $(\mathrm{p}=0.005)$ and lipid hydroperoxide $(\mathrm{p}=0.001)$ parameters were found to be decreased in OJI group compared to OJ group. Isoprostane $(\mathrm{p}=0.003)$ were found to be increased in OJI group compared to SI group.

Table I: Results of oxidative stress parameters

\begin{tabular}{|l|l|l|l|l|l|}
\hline & Sham & Sham+iloprost & OJ & OJ+iloprost & P value \\
\hline $8-O H d G(n g / m l)$ & $1.21 \pm 0.1$ & $1.16 \pm 0.2$ & $1.53 \pm 0.22^{*}$ & $1.13 \pm 0.25 \#$ & $\mathrm{p}=0.012$ \\
\hline Isoprostane (ng/ml) & $1.1 \pm 0.08$ & $1.05 \pm 0.14$ & $2.16 \pm 0.7^{* *}$ & $1.85 \pm 0.4$ & $\mathrm{p}=0.000$ \\
\hline $\begin{array}{l}\text { Protein carbonyl } \\
\text { (nmol/ml) }\end{array}$ & $30.91 \pm 12.33$ & $23.92 \pm 8.35$ & $40.46 \pm 7.36$ & $24.7 \pm 5.09 \# \#$ & $\mathrm{p}=0.02$ \\
\hline $\begin{array}{l}\text { Lipid hydroperoxide } \\
(\mathrm{Mmol} / \mathrm{ml})\end{array}$ & $1.96 \pm 0.39$ & $1.82 \pm 1.11$ & $5.11 \pm 1.66 \S$ & $1.85 \pm 1.01 \dagger$ & $\mathrm{p}=0.001$ \\
\hline
\end{tabular}

(8-OHdG: 8-Hydroxydeoxyguanosine; OJ: obstructive jaundice), $\$: \mathrm{p}$ value of the Kruskal-Wallis test. All parameters were comparable between the sham versus sham+iloprost groups. The sham group versus OJ group: *: $\mathrm{p}=0.006, * * \mathrm{p}=0.003, \S$ : $\mathrm{p}: 0.001$. The OJ group versus OJ+iloprost: $\#: \mathrm{p}=0.03$, \#\#: $\mathrm{p}=0.005, \uparrow: 0.001$.

\section{Histopathologic parameters}

There were no statistically significant differences in histologic parameters between S (Figure 1) and SI (Figure 2) groups. Bile stasis $(\mathrm{p}=0.001)$, portal inflammation $(\mathrm{p}=0.001)$, bile ductus proliferation $(\mathrm{p}=0.001)$ and cholangitis $(\mathrm{p}=0.001)$ parameters were found to be increased in OJ (Figure 3 ) group compared to $\mathrm{S}$ group.

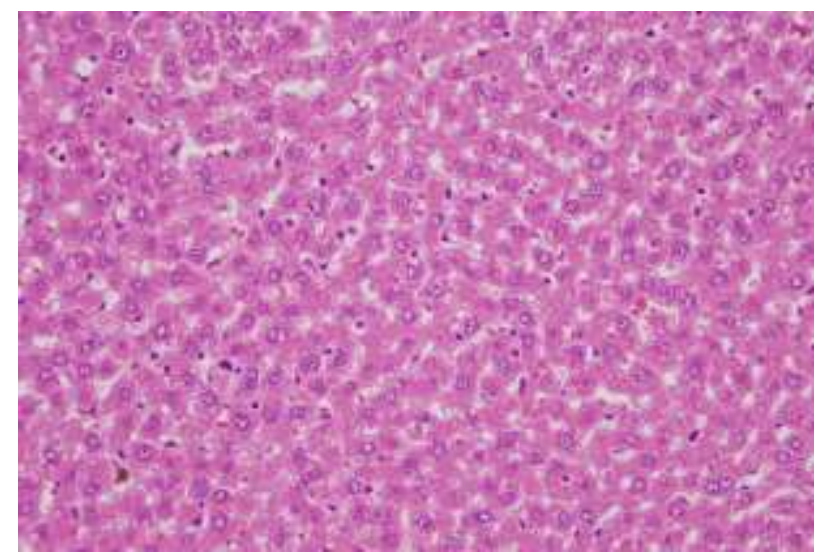

Figure 1: Control group. It's seen almost normal looking hepatocytes except mild hydropic changes. (HE x 400) 


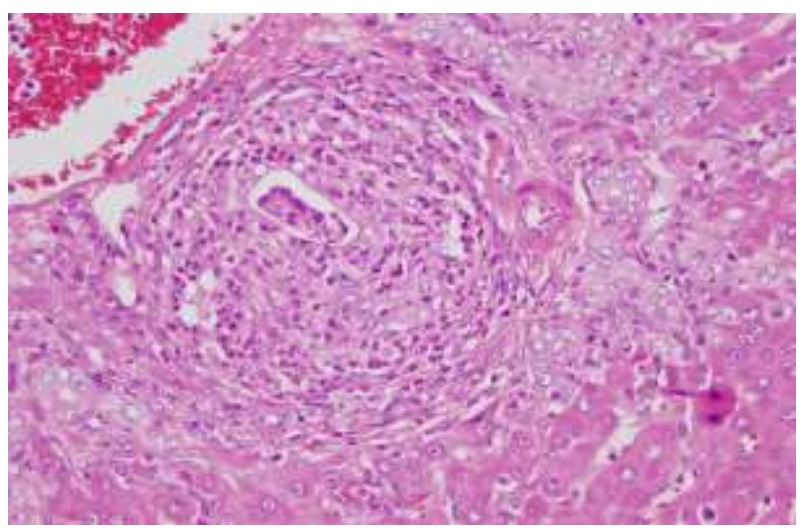

Figure 2. Iloprost group: Mixt inflammatory cells infiltrating portal area is associated with ductular proliferation.

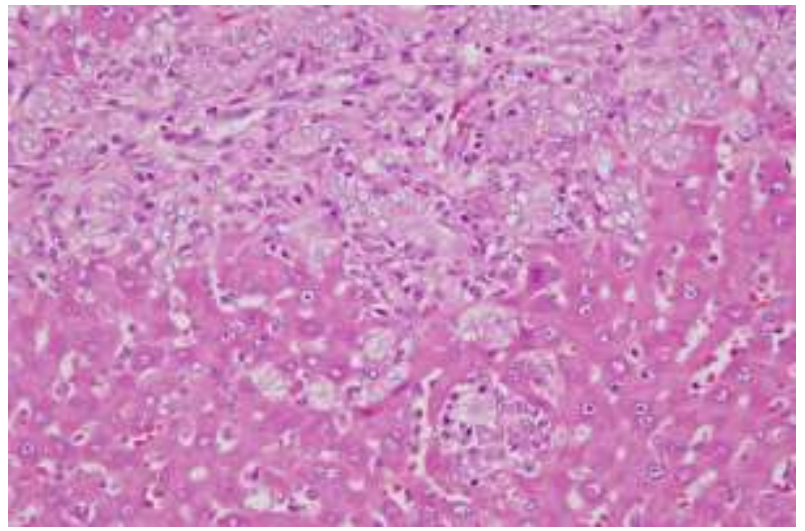

Figure 3. Cholangitis group: Prominent ductular proliferation and steatosis is seen

Hydropic degeneration $(\mathrm{p}=0.006)$, Kupffer cell proliferation $(\mathrm{p}=0.004)$, bile stasis $(\mathrm{p}=0.000)$, portal inflammation $(\mathrm{p}=0.001)$, bile ductus proliferation $(\mathrm{p}=0.000)$ and cholangitis $(\mathrm{p}=0.001)$ parameters were found to be increased in OJI group compared to SI group. No statistically significant differences were observed between OJ and OJI groups in histologic evaluation. Microabscess formation in liver were observed in one rat $(\mathrm{p}=0.37)$. The histopathologic results between of the $\mathrm{S}$ versus SI groups and OJ versus OJI groups were given (Table 2).

Table II: The results of histopathological evaluation.

\begin{tabular}{|l|l|l|l|l|l|}
\hline & Sham & Sham+iloprost & OJ & OJ+iloprost & $\mathrm{P}$ value \\
\hline Adiposity & 0 & 0 & 0 & 0 & $\mathrm{p}=0.089$ \\
\hline Hydropic degeneration & 0 & $0.25 \pm 0.16$ & $1.13 \pm 0.13$ & $1.29 \pm 0.18 \dagger$ & $\mathrm{p}=0.002$ \\
\hline $\begin{array}{l}\text { Kupffer cell } \\
\text { proliferation }\end{array}$ & 0 & $0.25 \pm 0.16$ & $1.13 \pm 0.13$ & $1.43 \pm 0.2 \dagger \dagger$ & $\mathrm{p}=0.002$ \\
\hline Bile stasis & 0 & 0 & $1^{*}$ & $1 \ddagger$ & $\mathrm{p}$ \\
\hline $\begin{array}{l}\text { Inflammatory } \\
\text { activity in the } \\
\text { portal space }\end{array}$ & 0 & $0.25 \pm 0.16$ & $2^{* *}$ & $1.86 \pm 0.14 \dagger \dagger$ & $\mathrm{p}=0.000$ \\
\hline Bile duct proliferation & 0 & $1.13 \pm 0.13$ & $2.89 \pm 0.13 \S$ & $2.86 \pm 0.14 \diamond$ & $\mathrm{p}=0.000$ \\
& & & & & \\
\hline Cholangitis & 0 & $1.13 \pm 0.13$ & $1.63 \pm 0.26 \S \S$ & $2 \pm 0.22$ & $\mathrm{p}=0.000$ \\
\hline $\begin{array}{l}\text { Microabscess } \\
\text { formation }\end{array}$ & 0 & 0 & 0 & $0.29 \pm 0.28$ & $\mathrm{p}=0.37$ \\
\hline
\end{tabular}

(OJ: obstructive jaundice), $\bullet: \mathrm{p}$ value of the Kruskal-Wallis test. All parameters were comparable between the sham versus sham+iloprost groups and OJ versus OJ+iloprost groups. The sham group versus OJ group: *: $p=0.001, * *: p=0.001, \S: \mathrm{p}: 0.001, \S \S: \mathrm{p}=0.001$. The sham+iloprost versus OJ+iloprost groups: $\uparrow: p=0.006, \uparrow \uparrow: p=0.004, \dagger: p=0.000, \uparrow: p=0.001, \diamond: p=0.000$. 


\section{Discussion}

Internal or external biliary drainage is the cure for obstructive jaundice. Our experimental obstructive jaundice model does not reflect real clinical scenario in general. Palliative drainage or definitive restoration bile flow can be achieved in majority of the patients with obstructive jaundice. However, high bilirubin levels may maintain in certain time period even after bile drainage or attempts to eliminate bile flow obstruction may fail. Under these circumstances prevention from the harmful effects of hyperbilirubinemia is needed until the definitive treatment. Since extrahepatic bile drainage obstructed permanently, severity of obstructive jaundice increased gradually during study period. Nevertheless, iloprost supplementation reduced DNA oxidation under gradually increasing hyperbilirubinemia. Since the liver has a high regeneration capacity and capable to regain its functions, protecting integrity of DNA may be beneficial during management of obstructive jaundice. Hyperbilirubinemia may be genotoxic via its oxidant effects (Basu et al. 2014). In addition to its use to monitor DNA damage, 8-OHdG has been suggested as a factor initiating carcinogenic pathways (Valavanidis 2009). An anti-metastatic effect of iloprost was shown decades ago (Sava et al. 1989, Honn ey al. 1981). Prostacyclin analogues may reduce risk of metastasis by interacting between tumor cell and host (Schneider et al. 1994). It has been shown that iloprost can be used in cancer patients safely for treatment of systemic sclerosis (Pehlivan et al. 2012). Iloprost may prevent genotoxicity under hyperbilirubinemic condition. However, there is no clinical evidence supporting antineoplastic effects of iloprost. We observed beneficial effects of iloprost on oxidative stress parameters, but there was no improvement in histological evaluation of the liver. As we mentioned above, we blocked the bile flow permanently and created a gradually increasing hyperbilirubinemic condition as an experimental model. This may be the major factor for not observing any favorable histologic results. Combination of antioxidants is proposed to provide synergistic effects and increase each others activity, and therefore combination of iloprost with other antioxidants may be analyzed to obtain better results on histological evaluation of the liver (Isik et al. 2015).

Obstructive jaundice complicates many vital functions maintaining homeostasis (Scott-Conner and Grogan 1994). High bile acid levels, systemic endotoxemia and associated inflammatory response, over expression of inducible nitric oxide synthase, increased neutrophil chemotaxis, superoxide anion production and decreased levels of vitamin E augment oxidative damage in obstructive jaundice (Sakaguchi et al. 1996, Tsai et al. 1997). Oxidative stress is hepatotoxic (Liu et al. 2001, Vendemiale et al. 2002). Biliary cholestasis induces lipid peroxidation by reducing antioxidant capacity (Pastor et al. 1997). Obstructive jaundice caused oxidative damage in our control group. Since our surgeons are experienced on obstructive jaundice model in rats with the same technique and we carry out continuous research on obstructive jaundice (Alturfan et al. 2014, Aydin et al. 2010) we did not measure blood bilirubin, aspartate aminotransferase and alanine aminotransferase to prove hyperbilirubinemia and associated liver damage biochemically in the rats which were included to this study for minimizing expenses of the biochemical analyses. Although there is some data regarding to antioxidant effect of iloprost (Erre and Passiu 2009), use of iloprost in OJ induced oxidative stress has been poorly studied. Considering the significant decrease in oxidative stress parameters in OJI group compared to OJ group, our results may reveal that iloprost decrease the oxidative damage caused by oxidative jaundice.

Nowadays, a growing number of studies have suggested that reduction of oxidative stress is considered to have an important role for the prevention of liver damage due to cholestasis (Shiesh et al. 2000, Padillo et al. 2004). The antioxidant mechanisms of iloprost are under investigation (Aytac et al. 2008, Aytac et al. 2006). Atherosclerosis, senescence and oxidative stress reduces prostacyclin production by inhibiting cyclooxygenase which is the major enzyme in prostanoids synthesis (Dembinska-Kiec et al. 1979, Whorton et al. 1985). Since oxidative stress causes endothelial dysfunction, prostacyclin production decreases (Giugliano et al. 1996). Lack of prostacyclin may worsen microcirculation and subsequently augment production of oxidants as a vicious cycle. Toxic effects of oxidants on endothelium well known for decades and obstructive jaundice complicates hepatic microcirculation (Sacks et al. 1978, Okava et al. 2008). Iloprost supplementation may ameliorate microcirculation, improve tissue oxygenation and reduce production of oxidants in obstructive jaundice. It has been clinically and experimentally shown that iloprost improves microvascular functions (Ciuffetti et al. 2003, Rasmussen et al. 1992). In our OJ group, iloprost may have decreased the oxidation of the proteins and lipids with its effect on hepatic microcirculation. 
In conclusion, iloprost supports antioxidant activity in obstructive jaundice without causing further liver damage in rats. New studies to explain molecular pathways of antioxidant activities supported by iloprost are needed.

The authors have nothing to disclose.

\section{References}

[1] Allameh A, Razavi-Azarkhiavi K, Mohsenifar A, Jamali-Zavarei M (2012). Effect of acute ethanol treatment on biochemical and histopathological factors in rat liver in an experimental sepsis model. Pathology, research and practice. 208(6): 331-7.

[2] Alturfan AA, Aytac E, Emekli-Alturfan E, Yarat A, Saribeyoglu K, Pekmezci S, et al (2014). Serum total sialic acid as a novel complementary candidate marker of hepatic damage in obstructive jaundice. Annals of clinical and laboratory science. 244(1): 56-61.

[3] Assimakopoulos SF, Vagianos CE, Zervoudakis G, Filos KS, Georgiou C, Nikolopoulou V, et al. (2004) Gut regulatory peptides bombesin and neurotensin reduce hepatic oxidative stress and histological alterations in bile duct ligated rats. Regulatory peptides. 120(1-3): 185-93.

[4] Assimakopoulos SF, Vagianos CE, Patsoukis N, Georgiou C, Nikolopoulou V, Scopa CD (2004). Evidence for intestinal oxidative stress in obstructive jaundice-induced gut barrier dysfunction in rats. Acta physiologica Scandinavica. 180(2):177-85.

[5] Assimakopoulos SF, Thomopoulos KC, Patsoukis N, Georgiou CD, Scopa CD, Nikolopoulou VN, et al (2006). Evidence for intestinal oxidative stress in patients with obstructive jaundice. European journal of clinical investigation. 36(3):181-7.

[6] Aydin S, Aytac E, Uzun H, Altug T, Mansur B, Saygili S, et al (2010). Effects of Ganoderma lucidum on obstructive jaundice-induced oxidative stress. Asian journal of surgery. 33(4): 173-80.

[7] Aytac E, Seymen P, Dikmen G, Uzun H, Seymen HO (2008). Iloprost pretreatment before unilateral nephrectomy: an experimental study in rats. Asian journal of surgery. 31(2): 69-74.

[8] Aytac E, Seymen HO, Uzun H, Dikmen G, Altug T (2006). Effects of iloprost on visual evoked potentials and brain tissue oxidative stress after bilateral common carotid artery occlusion. Prostaglandins, leukotrienes, and essential fatty acids. 74(6): 373-8.

[9] Basu S, De D, Dev Khanna H, Kumar A (2014). Lipid peroxidation, DNA damage and total antioxidant status in neonatal hyperbilirubinemia. Journal of perinatology: official journal of the California Perinatal Association. 34(7): 519-23.

[10] Ciuffetti G, Sokola E, Lombardini R, Pasqualini L, Pirro M, Mannarino E (2003). The influence of iloprost on blood rheology and tissue perfusion in patients with intermittent claudication. Kardiologia polska. 59(9): 197-204.

[11] Della Bella S, Molteni M, Mocellin C, Fumagalli S, Bonara P, Scorza R (2001). Novel mode of action of iloprost: in vitro down-regulation of endothelial cell adhesion molecules. Prostaglandins \& other lipid mediators. 65(2-3): 73-83.

[12] Dembinska-Kiec A, Rucker W, Schonhofer PS (1979). Atherosclerosis decreased prostacyclin formation in rabbit lungs and kidneys. Prostaglandins. 17(6): 831-8.

[13] Erre GL, Passiu G (2009). Antioxidant effect of Iloprost: current knowledge and therapeutic implications for systemic sclerosis. Reumatismo. 61(2): 90-7.

[14] Giugliano D, Ceriello A, Paolisso G (1996). Oxidative stress and diabetic vascular complications. Diabetes care. 19(3): 257-67.

[15] Grant SM, Goa KL (1992). Iloprost. A review of its pharmacodynamic and pharmacokinetic properties, and therapeutic potential in peripheral vascular disease, myocardial ischaemia and extracorporeal circulation procedures. Drugs. 43(6): 889-924.

[16] Guicciardi ME, Malhi H, Mott JL, Gores GJ (2013). Apoptosis and Necrosis in the Liver. Comprehensive Physiology. 3(2):10.1002/cphy.c120020.

[17] Honn KV, Cicone B, Skoff A (1981). Prostacyclin: a potent antimetastatic agent. Science (New York, NY). 212(4500): 1270-2. 
[18] Isik A, Peker K, Gursul C, Sayar I, Firat D, Yilmaz I, et al (2015). The effect of ozone and naringin on intestinal ischemia/reperfusion injury in an experimental model. International journal of surgery (London, England). 21: 38-44.

[19] Knodell RG, Ishak KG, Black WC, Chen TS, Craig R, Kaplowitz N, et al (1981). Formulation and application of a numerical scoring system for assessing histological activity in asymptomatic chronic active hepatitis. Hepatology 1(5): 431-5.

[20] Liu TZ, Lee KT, Chern CL, Cheng JT, Stern A, Tsai LY (2001). Free radical-triggered hepatic injury of experimental obstructive jaundice of rats involves overproduction of proinflammatory cytokines and enhanced activation of nuclear factor kappaB. Annals of clinical and laboratory science. 31(4): 383-90.

[21] Okaya T, Nakagawa K, Kimura F, Shimizu H, Yoshidome H, Ohtsuka M, et al (2008). Obstructive jaundice impedes hepatic microcirculation in mice. Hepato-gastroenterology. 55(88): 2146-50.

[22] Padillo FJ, Cruz A, Navarrete C, Bujalance I, Briceno J, Gallardo JI, et al (2004). Melatonin prevents oxidative stress and hepatocyte cell death induced by experimental cholestasis. Free radical research. 38(7): 697-704.

[23] Pain JA, Cahill CJ, Bailey ME (1985). Perioperative complications in obstructive jaundice: therapeutic considerations. The British journal of surgery. 72(12): 942-5.

[24] Pastor A, Collado PS, Almar M, Gonzalez-Gallego J (1997). Antioxidant enzyme status in biliary obstructed rats: effects of $\mathrm{N}$-acetylcysteine. Journal of hepatology. 27(2): 363-70.

[25] Pehlivan Y, Turkbeyler IH, Balakan O, Sevinc A, Yilmaz M, Bakir K, et al (2012). Possible antimetastatic effect of iloprost in a patient with systemic sclerosis with lung cancer: a case study. Rheumatology international. 32(5): 1437-41.

[26] Rasmussen I, Arvidsson D, Zak A, Haglund U (1992). Splanchnic and total body oxygen consumption in experimental fecal peritonitis in pigs: effects of dextran and iloprost. Circulatory shock. 36(4): 299-306.

[27] Sacks T, Moldow CF, Craddock PR, Bowers TK, Jacob HS (1978). Oxygen radicals mediate endothelial cell damage by complement-stimulated granulocytes. An in vitro model of immune vascular damage. The Journal of clinical investigation. 61(5): 1161-7.

[28] Sakaguchi S, Furusawa S, Yokota K, Sasaki K, Takayanagi M, Takayanagi Y (1996). The enhancing effect of tumour necrosis factor-alpha on oxidative stress in endotoxemia. Pharmacology \& toxicology. 79(5): 259-65.

[29] Sava G, Perissin L, Zorzet S, Piccini P, Giraldi T (1989). Antimetastatic action of the prostacyclin analog iloprost in the mouse. Clinical \& experimental metastasis. 7(6): 671-8.

[30] Schneider MR, Tang DG, Schirner M, Honn KV(1994). Prostacyclin and its analogues: antimetastatic effects and mechanisms of action. Cancer metastasis reviews. 13(3-4): 349-64.

[31] Scott-Conner CE, Grogan JB (1994). The pathophysiology of biliary obstruction and its effect on phagocytic and immune function. The Journal of surgical research. 57(2): 316-36.

[32] Shiesh SC, Chen CY, Lin XZ, Liu ZA, Tsao HC (2000). Melatonin prevents pigment gallstone formation induced by bile duct ligation in guinea pigs. Hepatology (Baltimore, Md). 32(3): 455-60.

[33] Tsai LY, Lee KT, Lu FJ (1997). Biochemical events associated with ligation of the common bile duct in Wistar rats. Journal of the Formosan Medical Association, Taiwan yi zhi. 96(1): 17-22.

[34] Vasiliadis K, Pramateftakis MG, Blouhos K, Mantzoros I, Koliakos G, Zaraboukas T, et al (2007). Effect of iloprost on impaired anastomotic healing caused by 5-fluorouracil plus leucovorin. Diseases of the colon and rectum. 50(6): 899-907.

[35] Valavanidis A, Vlachogianni T, Fiotakis C (2009). 8-hydroxy-2' -deoxyguanosine (8-OHdG): A critical biomarker of oxidative stress and carcinogenesis. Journal of environmental science and health Part C, Environmental carcinogenesis \& ecotoxicology reviews. 27(2): 120-39.

[36] Vendemiale G, Grattagliano I, Lupo L, Memeo V, Altomare E (2002). Hepatic oxidative alterations in patients with extra-hepatic cholestasis. Effect of surgical drainage. Journal of hepatology. 37(5): 601-5.

[37] Whorton AR, Montgomery ME, Kent RS (1985). Effect of hydrogen peroxide on prostaglandin production and cellular integrity in cultured porcine aortic endothelial cells. The Journal of clinical investigation. 76(1): 295-302. 